\title{
Edition der Briefe von und an Matthias und Rebecca Claudius
}

Handschriften von Briefen von und an Matthias Claudius und Frau Rebecca werden für ein kritisches Verzeichnis des Briefwechsels gesucht. Auf seiner Grundlage plant die Joachim-Jungius-Gesellschaft der Wissenschaften, Hamburg, eine kritische und kommentierte Gesamtausgabe. - Private und institutionelle Besitzer werden um Hinweise und Meldungen gebeten an

Prof. Dr. Jörg-Ulrich Fechner

Ruhr-Universität Bochum

Germanistisches Institut

D-44780 Bochum 